No. 40

A Dynamic Model of Fiscal Reconstruction

\author{
Toshihiro lhori* \\ \& Jun-ichi Itaya**
}

April 1997

* Department of Economics, University of Tokyo

* Department of Economics, Otaru University of Commerce 


\title{
A Dynamic Model of Fiscal Reconstruction
}

\author{
by \\ Toshihiro Ihori* and Jun-ichi Itaya ${ }^{\mathrm{b}}$
}

April 1997

\begin{abstract}
This paper investigates dynamic properties of fiscal reconstruction by analyzing the infinite duration dynamic game among various interest groups with a framework of voluntary acceptance of tax burden. By comparing the first best solution, the open-loop solution under enforceable commitments, and the closed-loop solution without commitment, we explore the free riding aspect of fiscal reconstruction process and investigate the normative role of consumption taxes to internalize the free riding problem. We also derive explicitly the adjustment speeds of fiscal reconstruction under alternative solutions and examine the impact of consumption taxes on the adjustment speed.
\end{abstract}

Key words: fiscal reconstruction, dynamic provision, welfare JEL classification numbers: H41, F13, D62

*a: Corresponding author: Department of Economics, University of Tokyo, Hongo, Tokyo 113, Japan, (phone) 03-3812-2111, (fax) 03-3818-7082, E-mail:ihori@e.utokyo.ac.jp

b: Department of Economics, Otaru University of Commerce, 3-5-21 Midori, Otaru, Hokkaido 047, Japan, (phone) 0134-27-5200, (fax) 0134-27-5213 


\section{Introduction}

Most developed countries are suffering from huge government deficits. This is partly due to a slowdown of economic growth in recent years. When national income does not grow much, tax revenue will not increase either. On the contrary, public spending and transfer payments have been gradually raised due to political pressures of interest groups, resulting in large budget deficits. Many governments are attempting to return to the balanced budget by raising taxes and/or reducing public spending. One of the most common measures is to introduce or raise a general consumption tax mainly because this tax would impose uniform shares of the tax burden on all parties in a nation. This is called the fiscal reconstruction movement.

Since fiscal reconstruction usually takes much time and public asset balances change over time, it is important to explore dynamic properties of fiscal reconstruction process. Futagami (1989) explored a dynamic game between the government and the public by using a two-person noncooperative differential game and investigated the properties of consumption taxes which are used to overcome government deficits. He found that there is an optimal upper bound of consumption tax rate in order to minimize the terminal stock of government debts. Alesina and Drazen (1991) presented a simple model of delayed stabilization due to a war of attrition among various interest groups and derived the expected time of stabilization as a function of characteristics of those groups. According to their analysis, the delay of stabilization is caused not only by heterogeneity in terms of the cost of waiting associated with the distortions resulting from distortionary financing (which are borne by the interest groups), but also by uncertainty about such a cost which leads each interest group to believe the possibility that another group concedes earlier to accept a larger share of the burden for stabilization. 
In light of the observations of actual fiscal reconstruction it seems to us that the war-of-attrition model of Alesina and Drazen is limited in a number of ways. First, since the fiscal reconstruction process usually proceeds through bargaining and negotiating over a long time, the interest groups involved have known their costs and benefits resulting from fiscal reconstruction each other. Under such circumstances uncertainty about the cost of waiting may be of little importancel. Second, they focused only on the costs associated with unsuccessful fiscal reconstruction, while ignoring the gains from successful fiscal reconstruction. After fiscal reconstruction is successfully completed, the government can obtain the greater freedom on how to spend its budget instead of paying interest payments on outstanding government bonds, so that it can spend more on the provision of public goods and social welfare spending. These expenditures contribute to improving the welfare of various interest groups. In order to obtain such benefits, therefore, those interest groups may be willing to voluntarily accept tax increases or give up their group-specific privileges to some extent. Third, in their model the government is assumed to use nondistortionary methods of raising its revenue after the stabilization; however, this assumption would not be consistent with actual fiscal reconstruction, since in practice the fiscal reconstruction has been accomplished through large cuts in government expenditures and tax increases via either indirect or direct distortionary taxes. Regardless of whether indirect or direct taxes are adopted, we have to bear the distortionary costs associated

1. Alesina and Tabellini (1990) emphasized a different type of uncertainty, that is, uncertainty about who will be appointed in the future prevents the current government from fully internalizing the cost of leaving debt to its successor. As a result, the equilibrium level of public debt tends to be larger than it is socially optimal. This type of uncertainty does not at least provide a proper account for Japan's recent huge government deficits despite the fact that the Liberal Democratic Party consistently maintains control of 
with levying those taxes after the stabilization.

Those drawbacks provide motivations of the present paper. More specifically, instead of the war-of-attrition model we shall develop a dynamic game among various interest groups which would accept voluntarily increases in their net tax burden (or abandon voluntarily some of group-specific privileges) in order to gain the benefits resulting from a reduction in government debts without appealing to ad-hoc uncertainty which has secondary importance. We believe that the critical point of formulating the process of fiscal reconstruction is to clarify how the existing privileges of interest groups such as preferential treatments of taxes and/or subsidies are to be abandoned ${ }^{2}$. The marginal benefit of doing so is an increase in public spending since an increase in net tax payments by each group can reduce the size of deficits and thus interest payments on public debt. The marginal cost of that is a decrease in private consumption since an increase in its net tax payments reduces disposable income of each group. They are therefore willing to abandon some of these privileges only if the marginal benefit would outweigh the marginal cost. The rationale for this approach is not that we believe that the stabilization approach using a war of attrition model is unimportant. Rather, the aim of this paper is to demonstrate that even if there were neither uncertainty about the cost of waiting nor heterogeneity in terms of such a cost, we could analyze fiscal reconstruction as a dynamic game among various interest groups. This paper, therefore, is intended as a complement to the war-of-attrition

the parliament as an unbroken majority.

2. For example, in Japan the bureaucracy, politicians, and agricultural cooperatives (nokyo) form the ruling triad of the agricultural sector. Some politicians (zoku) have acquired experience and influence in sectoral economic management, and the role of party zoku is crucial in creating the consensus and in determining how the cuts are to be distributed among related but conflicting interest groups. 
model of Alesina and Drazen.

Bliss and Nalebuff (1984) examined the decision of how a private individual decides when to take the initiative and pay for the provision of a public good. Fershtman and Nitzan (1991) considered a dynamic public good contribution game in which individuals' contributions are accumulated over time ${ }^{3}$. They showed that the free riding problem is aggravated when players' contributions are conditional on the observable collective contributions although the utility function is linear and the ad-hoc adjustment costs function is assumed. We apply their theoretical framework to the fiscal reconstruction problem by assuming that a number of interest groups voluntarily pay taxes or accept cuts in subsidies to obtain more public spending under more general preferences of each interest group. We also explore the normative role of consumption taxes to attain the Pareto-efficient fiscal reconstruction by internalizing the free riding problem in an intertemporal setting. Furthermore we explicitly derive the adjustment speeds of fiscal reconstruction under alternative solutions of dynamic games and examine the effect of consumption taxes on the adjustment speed. We shall praise a general consumption tax as an effective means of helping the fiscal reconstruction process in a way that makes its adjustment path closer to a Pareto efficient one.

Section 2 presents the model. Section 3 investigates the Pareto efficient outcome. Section 4 considers the open-loop solution under enforceable commitments. Section 5 considers the closed-loop solution without commitment. Section 6 introduces consumption taxes and derives the optimal level of consumption taxes to attain the Pareto-efficient fiscal reconstruction in the long run. Section 7 investigates the adjustment speed under alternative solutions of dynamic games. Finally, section 8 concludes the paper. Mathematical derivations are found in the Appendix. 


\section{The model}

There are many $(n \geq 2)$ interest groups in the small open economy. Each of them enjoys a group-specific privilege of smaller taxes and/or higher subsidies which may be used for private consumption. For analytical simplicity, the instantaneous utility of group $\mathrm{i}$ (or agent i) is assumed to be separable in consumption $c_{i}$ and public spending $G$ for group i, which is common to all groups and may be viewed as a pure public good, i.e.,

$$
\begin{aligned}
& \begin{aligned}
U^{i}\left(c_{i}, G\right) & =U_{1}^{i}\left(c_{i}\right)+U_{2}^{i}(G) \\
& =\alpha^{i}+\beta_{1}^{i} c_{i}-\frac{\gamma_{1}^{i}}{2} c_{i}^{2}+\beta_{2}^{i} G-\frac{\gamma_{2}^{i}}{2} G^{2}
\end{aligned} \\
& \beta_{1}, \beta_{2}, \gamma_{1}, \gamma_{2}>0
\end{aligned}
$$

which ensures that $c_{i}$ and $G$ are normal goods. Moreover, in order to be able to obtain analytical solutions, a second-order Taylor-series approximation of the above utility function is employed. This specification enables a comparison of different game equilibria as well as a sensitivity (or transitional) analysis with respect to the underlying parameters of the model. The intertemporal utility function of group $\mathrm{i}$ for the infinite-horizon problem starting at time 0 is given by

$$
\int_{0}^{\infty}\left[U_{1}^{i}\left(c_{i}\right)+U_{2}^{i}(G)\right] e^{-\rho t} d t
$$

where $\rho(>0)$ is the constant discount rate, which is common to all groups.

Public spending $G$ is determined by

$$
G=G^{*}-r B
$$

where $G^{*}$ is an exogenously given spending level, $r$ is the exogenously given foreign

3. See also Fershtman and Famien (1987) and Ihori and Itaya (1997). 
rate of interest, and $B$ is external government debt. Equation (3) means that the total government spending including interest payments is fixed at the level of $G^{*}$ through time, so that higher public spending $G$ is possible only by reducing the external debt outstanding $B$. During the fiscal reconstruction process many countries have actually imposed the ceiling constraint on the total spending in order to prevent a further deterioration in budget deficits. Equation (3) formulates such a ceiling rule. The strict ceiling rule of (3) (i.e., constancy of $G^{*}$ ) is adopted only for simplicity. A more general ceiling rule could be employed with the analytical results intact. ${ }^{4}$

The pubic debt, $B$, will change over time, following the government budget constraint. The dynamic evolution of $B$ is given by

$$
\dot{B}=G+r B-\sum_{i=1}^{n} g_{i}
$$

where $g_{i}$ is net payment of taxes provided by group i. This is the general income tax payment common to all groups minus group-specific privileges. An agreement to reconstruct the fiscal system towards balanced budget can be thought of as a voluntary one on how the increases in net taxes are to be apportioned between different interest groups. We therefore assume that each interest group voluntarily accepts increases in taxes or cuts in subsidies to accomplish fiscal reconstruction, given the Nash conjectures formed by the group at some appropriate point in time.

From equations (3) and (4) we have

\footnotetext{
4. When interest payments on public debt $r B$ increase, the government has three choices; increasing taxes, reducing spending, or issuing more debt. Fiscal reconstruction means that the last choice is unsustainable. It would not be optimal to employ the second choice alone if taxes are distortionary. Hence, an increase in $r B$ corresponds to a decrease in $G$ as well as an increase in $T$. This is a typical movement we would like to investigate. All we need below is the negative relation between $G$ and $r B$.
} 


$$
\dot{G}=r \sum_{i=1}^{n} g_{i}-r \cdot
$$

Group i's flow budget constraint is given by

$$
c_{i}+g_{i}=Y_{i}
$$

where $Y_{i}$ is exogenously given income of interest group $\mathrm{i}$ and the relative price of two goods is set to be unity. To focus on the problem at hand, these variables are assumed to be fixed through time ${ }^{5}$. In particular, although the assumption that $Y$ is fixed over time may appear to be extremely strong within a dynamic setting, it would be defended by the following two reasons. First, based on the experiences of many advanced countries facing large budget deficits, it turns out that the balanced budget movement occurs in the economy where the growth rate of GNP is close to zero and so GNP is nearly fixed over time. Second, the full optimization of private agents with perfect foresight within an infinite horizon framework would lead to the debt neutrality proposition of alternative financing of government spending. Therefore, the concept of optimal deficit would lose its policy meaning (unless distortionary taxes are explicitly introduced). In order to discuss the meaningful government deficit problem, we assume that private savings as well as private bequests are absent due to the liquidity or borrowing constraint and hence disposable income is exogenously fixed. 5,7

5. If the economy does not grow, the grow th in government deficit may not be consistent in the long run.

6 . If we allow for private lending or borrowing, the private sector would be willing to borrow as much as possible when $\mathrm{r}<\rho$ and vice versa. Suppose there exists an exogenous limit of lending or borrowing; in other words, capital markets are imperfect. Then equation (6) [i.e., the absence of private savings in (6)] still holds if income is now redefined to include interest payments from external lending.

7. As for the debt neutrality proposition, see Barro (1974). Roubini and Milesi-Ferretti (1994) sowed that if distortionary taxes are introduced into the infinite horizon framework, it is optimal to tax capital in the short run and to accumulate public asset, so that the long 
3. Cooperative behavior: Pareto efficient outcome

We first investigate the Pareto efficient outcome as a reference point. Pareto efficient outcomes for the differential game are found from solving the following problem:

$$
\operatorname{Max} \sum_{i=1}^{n} \int_{0}^{\infty}\left\{U_{1}^{i}\left(c_{i}\right)+U_{2}^{i}(G)\right\} e^{-\rho t} d t
$$

subject to (5), (6) and the initial stock of public asset $G(0)$. Before solving this problem, substitute (6) into (5) and (1). The utility function (1) may be rewritten as follows:

$$
U_{1}^{i}(c)+U_{2}^{i}(G)=\tilde{\alpha}^{i}+\widetilde{\beta}_{1}^{i} g_{i}-\frac{\gamma_{1}^{i}}{2} g_{i}^{2}+\beta_{2}^{i} G-\frac{\gamma_{2}^{i}}{2} G^{2}
$$

where

$$
\begin{aligned}
& \tilde{\alpha}^{i} \equiv \alpha^{i}+\beta_{1}^{i} Y_{i}-\frac{\gamma_{1}^{i}}{2} Y_{i}^{2} \\
& \tilde{\beta}_{1}^{i} \equiv-\beta_{1}^{i}+\gamma_{1}^{i} Y_{i}(<0)
\end{aligned}
$$

We assume that $\tilde{\beta}_{1}^{i}<0$, which comes from the usual assumption that the marginal utility of consumption is positive. At the Pareto efficient solution the liquidity constraint of private sector is not binding since the government can effectively control the intertemporal allocation of private consumption by adjusting government deficits.

After substituting (6) into (8), the current value Hamiltonian is given by

$$
H \equiv \sum_{i \neq 1}^{n}\left\{U_{1}^{i}\left(Y-g_{i}\right)+U_{2}^{i}(G)\right\}+\mu\left[\sum_{i=1}^{n} r g_{i}-r G^{*}\right]
$$

where $\mu$ is the shadow price associated with the accumulation of public spending.

run tax revenue is zero and public spending is financed by interest returns on public asset in the long-run equilibrium. 
Hence, the first order conditions are given as

$$
\begin{aligned}
& \frac{\partial H}{\partial g_{i}}=\frac{\partial U_{1}^{i}}{\partial c_{i}}(-1)+\mu r=0 \\
& \dot{\mu}-\rho \mu=-\frac{\partial H}{\partial G}=-\sum_{i=1}^{n} \frac{\partial U_{2}^{i}}{\partial G}
\end{aligned}
$$

In what follows, we assume for simplicity that groups are identical with respect to preferences as well as income. Since

$$
U_{c} \equiv \frac{\partial U_{1}}{\partial c}=\beta_{1}-\gamma_{1} c
$$

equation (10-1) reduces to

$$
g_{i}=Y-\frac{1}{\gamma_{1}}\left(\beta_{1}-\mu r\right)
$$

and equation (10-2) also reduces to

$$
\dot{\mu}=\rho \mu-n U_{G}
$$

where $U_{G} \equiv \partial U_{2} / \partial G=\beta_{2}-\gamma_{2} G$.

At the steady state from the condition $(10-2)^{\prime}=0$ we have

$$
\mu=\frac{n\left(\beta_{2}-\gamma_{2} G\right)}{\rho}
$$

Substituting (11) into (10-1)', we also have

$$
g_{i}=\kappa_{1}^{p}+\kappa_{2}^{p} G
$$

where

$$
\begin{aligned}
& \kappa_{1}^{p} \equiv Y-\frac{\beta_{1}}{\gamma_{1}}+\frac{\beta_{2}}{\gamma_{1}} \frac{n r}{\rho}>0 \\
& \kappa_{2}^{p} \equiv-\frac{\gamma_{2}}{\gamma_{1}} \frac{n r}{\rho}<0
\end{aligned}
$$

From the condition (5) $=0$ and using the assumption of symmetry in the long run, 


$$
n g=G^{*}
$$

Or

$$
n Y=n c+n g
$$

Substituting (12) into $g$ in (13) and solving for the Pareto efficient level of $G$ yields

$$
\bar{G}^{P}=\frac{n \kappa_{1}^{p}-G^{*}}{-n \kappa_{2}^{p}}=\frac{n\left(Y-\frac{\beta_{1}}{\gamma_{1}}+\frac{\beta_{2}}{\gamma_{2}} \frac{n r}{\rho}\right)-G^{\cdot}}{\frac{\gamma_{2}}{\gamma_{1}} \frac{r n^{2}}{\rho}}
$$

Alternatively, from (10-1) and the condition $(10-2)^{\prime}=0$ we have

$$
n \frac{U_{G}}{U_{c}}=\frac{\rho}{r}
$$

Equations (13) and (15) together determine the steady state Pareto-efficient values of $G$ [given explicitly by equation (14)] and $c$. Figure 1 shows the feasibility condition (13) at the steady state as vertical line $A B$. The Pareto efficient solution at the steady state is given by point $\mathrm{P}$, where condition (15) is satisfied on line $A B$. Equation (15) can be viewed as the dynamic version of familiar Samuelson's rule for the optimal provision of public goods. From equation (3) the steady state (desired) level of external debt is given by

$$
\bar{B}^{P}=\frac{1}{r}\left(G^{*}-\bar{G}^{P}\right)
$$

An increase in $G^{*}$ will reduce $\bar{G}^{p}$ via (14) and hence raise $\bar{B}^{P}$ via (3)'. Intuitively, higher $G^{*}$ implies higher tax payments by every group, thereby reducing their disposable income. The decreased disposable income depresses the demand for public spending thus raising $\bar{B}^{P}$. In contrast, it follows that $Y$ will raise $\bar{G}^{p}$ via (14) and hence reduce $\bar{B}^{P}$. This is clearly due to the positive income effect.

Equation (14) [or (15)] means that $\bar{G}^{p}$ is increasing with $r / \rho$ and $n$, while the 
steady state levels of private consumption (c) and of tax payments $(g)$ both remain constant by virtue of (13). Since an increase in $G$ has to be accompanied by a corresponding decrease in $B$ so as to satisfy (3), a higher rate of interest implies an increase in the cost of per-capita public debt thus raising the marginal cost of public debt. An increase in $\rho$ implies a higher rate of discounting the future utilities from $G$ and thus an increase in the marginal cost of $G$ (a decrease in the marginal cost of $B$ ). Since an increase in the number of groups implies an increase in the number of those who receive the benefits of $G$ and thus in the total marginal utility of $G$, the demand for $G$ is stimulated.

\section{The open-loop strategies}

Let us investigate the open-loop strategies. This type of Nash equilibrium concept presumes that the contribution to tax revenue made by each group in the fiscal reconstruction process at each point in time is only conditioned on the initial stock of public debt and hence the initial level of public spending, $G(0)$, and that each group precommits itself to a path of contribution. It follows that the expected contributions of the others do not depend on past or current stocks or on past or current contributions of each group.

The problem is formulated as follows:

Maximize (2) subject to (5), (6) and the exogenously given $G(0)$ and $g_{j}(t) j \neq i$ at time 0.

The first order conditions are as follows

$$
\begin{aligned}
& U_{c}(-1)+\mu r=0 \\
& \mu-\rho \mu=-U_{G}
\end{aligned}
$$


We now have

$$
g_{i}=\kappa_{1}^{o}+\kappa_{2}^{o} G
$$

where

$$
\begin{aligned}
& \kappa_{1}^{0} \equiv Y-\frac{\beta_{1}}{\gamma_{1}}+\frac{\beta_{2}}{\gamma_{1}} \frac{r}{\rho}>0 \\
& \kappa_{2}^{0} \equiv-\frac{\gamma_{2}}{\gamma_{1}} \frac{r}{\rho}<0
\end{aligned}
$$

Compare between the steady-state level of public spending under the Pareto efficient solution $\left(\bar{G}^{P}\right)$ and that under the open-loop Nash equilibrium $\left(\bar{G}^{\circ}\right)$. The steady-state level of $\bar{G}^{\circ}$ is given as

$$
\bar{G}^{o}=\frac{n \kappa_{1}^{o}-G^{\circ}}{-n \kappa_{2}^{o}}
$$

Alternatively, from (16-1) and (16-2) in the steady state we have

$$
\frac{U_{G}}{U_{c}}=\frac{\rho}{r}
$$

Thus, as shown in Figure 1, the open-loop steady state equilibrium is given by point $O$, which satisfies (19) on line $\mathrm{AB} . \quad U_{G} / U_{c}$ given by (19) is greater than $U_{G} / U_{c}$ given by (15). Equation (19) means that the per-group marginal benefit of $G$ is equal to the marginal cost of $G$, while equation (15) means that the total marginal benefit of $G$ is equal to the marginal cost of $G$. Since the marginal rate of substitution of $G$ with respect to $c$ is greater at point $O$ than at point $\mathrm{P}, G$ is too little, $C$ is too much, and $B$ is too much at point $\mathrm{O}$ compared with the Pareto efficient allocation.

Since the open-loop Nash equilibrium is the dynamic counterpart of the static Nash equilibrium, the resulting under-provision of public spending (i.e., higher outstanding of public debt and lower welfare achievement of fiscal reconstruction) in the stcady state is the dynamic version of the well-known under-provision of the 
voluntarily supplied public good at the static Nash equilibrium [Bergstrom et.al. (1986)]. From (19) it is clear that the steady state effects on $c . g$, and $G$ at the open-loop solution are qualitatively the same as those at the Pareto efficient solution. Although $\bar{G}^{O}$ increases monotonically with the number of groups like $\bar{G}^{P}$, they approach different limit values as the number of groups becomes infinity; moreover,

$$
\lim _{n \rightarrow \infty} \bar{G}^{0}<\lim _{n \rightarrow \infty} \bar{G}^{P}<\infty
$$

Needless to say, the smaller limit value of $\bar{G}^{o}$ is due to a free-riding tendency of interest groups which play open-loop strategies. This result again coincides with that at the static Nash equilibrium [see, McGuire (1974) among others].

\section{Perfect Nash equilibrium}

The closed-loop (or subgame perfect) Nash equilibrium allows each interest group to condition its contribution to tax revenues on the current and past stocks of public debt and levels of public spending. The subgame perfect Nash equilibrium requires that for each subgame the relevant part of the set of strategies be in Nash equilibrium. The subgame-perfect or feedback Nash equilibrium can be found by using dynamic programming.

Let $V^{i}(G)$ be the value of group $i$ of the game that starts at $G(0)=G$. Using the value function approach the feedback equilibrium strategies must satisfy the following Jacobi-Bellman condition:

$$
\begin{aligned}
& \rho V^{i}(G)=\underset{g_{i}}{\operatorname{Max}}\left[\tilde{\alpha}+\widetilde{\beta}_{1} g_{i}-\frac{\gamma_{1}}{2} g_{i}^{2}+\beta_{2} G-\frac{\gamma_{2}}{2} G^{2}\right. \\
& \left.+V_{G}^{i}\left\{\sum_{i=1}^{n} r g_{i}-r G\right\}\right]
\end{aligned}
$$

Since the right hand side of (20) is concave with respect to $g_{i}$, the $g_{i}$ that maximizes it is given by 


$$
g_{i}=\frac{1}{\gamma_{1}}\left(\tilde{\beta}_{1}+V_{G}^{i} r\right)
$$

As shown in Appendix 1, we have

$$
\begin{aligned}
& g_{i} \equiv \kappa_{1}^{s}+\kappa_{2}^{s} G \\
& \kappa_{1}^{s} \equiv \frac{\tilde{\beta}_{1}}{\gamma_{1}}+\theta_{1} r=Y-\frac{\beta_{1}}{\gamma_{1}}+r \frac{\lambda_{1} n r \tilde{\beta}_{1}+\beta_{2}-\gamma_{1} \lambda_{1} r G^{*}}{\gamma_{1} \rho-(2 n-1) \gamma_{1} \lambda_{1} r^{2}}>0 \\
& \kappa_{2}^{s}=r \lambda_{1}=\frac{\frac{\rho}{2}-\sqrt{\left(\frac{\rho}{2}\right)^{2}+\frac{\gamma_{2}}{\gamma_{1}} r^{2}(2 n-1)}}{r(2 n-1)}<0
\end{aligned}
$$

At the steady state we have

$$
\bar{G}^{s}=\frac{n \kappa_{1}^{s}-G^{*}}{-n \kappa_{2}^{s}}
$$

Alternatively, equation (21) can be rewritten as

$$
U_{c}=V_{G} r=\left(\theta_{1} \gamma_{1}+\theta_{2} \gamma_{1} G\right) r
$$

Using (24), Appendix 3 shows

$$
\frac{\rho V_{G}}{U_{G}}<1 \text { and } U_{c}<\frac{U_{G} r}{\rho}
$$

at the closed loop solution.

As shown in Figure 1, the closed-loop solution is given by point $S$, which satisfies the second inequality in (25). Since the marginal rate of substitution of $G$ at point $\mathrm{S}$ is greater than that at point $\mathrm{O}, G$ is too little, $c$ is too much, and hence $B$ is too much at point $S$, compared with point $O$. In conjunction with the comparative steady state result of the open-loop solution in the previous section, moreover, we have the following welfare ranking:

$$
U\left(c, \bar{G}^{s}\right)<U\left(c, \bar{G}^{o}\right)<U\left(c, \bar{G}^{P}\right)
$$


The free riding problem is further aggravated when players' contributions are conditional on the observable current collective contributions compared with that at the open-loop solution. Without commitment the resulting public debt therefore is higher than that with the enforceable commitment case.

The economic insight behind the result is almost the same as that of Fershtman and Nitzan (1991) in which the contributions of the group to tax revenues are strategic substitutes in the sense that aggressive behavior (lower contribution to tax revenues) by one group leads to less aggressive behavior (higher contribution to tax revenues) by the other group. Moreover, note from (23) that although $\bar{G}^{s}$ is positively related to $\rho$, the effects of $n$ or $r$ on $\bar{G}^{s}$ are ambiguous (recall that $\bar{G}^{P}$ and $\bar{G}^{o}$ are unambiguously increasing with $r / \rho$ and $n$ ). The reason for these ambiguities is that the higher $r$ or $n$, the more willing every group is to contribute; such less aggressive behavior in turn leads to contribute less due to the property of strategic substitutes, thereby offsetting the first effect. It should also be noted that the limit of $\bar{G}^{s}$ is indeterminate when the number of groups becomes infinity. This is because a rise in the number of groups again creates the above two conflicting effects on $\bar{G}^{s}$.

\section{Optimal consumption tax policy}

We now introduce a general consumption tax and investigate the normative role of tax policy to internalize the free riding aspect of fiscal reconstruction process. With a consumption tax rate, $\tau$, the budget constraint (6) is rewritten as

$$
(1+\tau) c_{i}+g_{i}=Y_{i}+T_{i}
$$

where $T_{i}$ is a lump-sum transfer given to group $i$. The government budget constraint can now be expressed by 


$$
\dot{B}=G+r B-\sum_{i=1}^{n} g_{i}-(1-\varepsilon) \sum_{i=1}^{n} \tau c_{i}
$$

where $\varepsilon\left(=\sum T_{i} / \sum \tau c_{i}\right)$ is the portion of consumption taxes that is used for lump sum transfers. Some of revenue from consumption taxes will be returned to the private sector in a lump-sum way. General consumption taxes are usually regarded as the most powerful measure to raise a large amount of tax revenue since the tax base is very broad. This is the revenue effect. The consumption tax also changes the relative price of private consumption in terms of voluntary taxes, inducing substitution from $c$ to $g$. This is the substitution effect. We can compare the revenue effect and the substitution effect of consumption taxes by introducing the propensity to transfer (i.e., $\varepsilon$ ).

First, we consider the open-loop strategies. In the open-loop case we now have in place of (16-1)

$$
-U_{c} \frac{1}{1+\tau}+\mu\left[r-\frac{(1-\varepsilon) r \tau}{1+\tau}\right]=0
$$

Thus, at the open loop solution in place of (19)

$$
\frac{U_{G}}{U_{c}}=\frac{\rho}{r(1+\varepsilon \tau)}
$$

In order to realize the Pareto efficient allocation at the open-loop steady-state solution, considering (15), we need the following equality:

$$
\frac{\rho}{r(1+\varepsilon \tau)}=\frac{\rho}{r n}
$$

Thus, the optimal consumption tax rate at the open-loop steady-state solution, $\tau^{o}$, is given by

$$
\tau^{o}=\frac{n-1}{\varepsilon}
$$

which is increasing with the number of groups noting that if $n=1, \tau^{o}=0$ and 
decreasing with the portion of consumption taxes to be used for lump-sum transfers. When $\varepsilon$ is low, the government deficit is likely to be offset by revenues from consumption taxes. It follows that the marginal benefit of fiscal reconstruction for each interest group is low and hence it would not be likely to make each group abandon its privileges easily. Hence, the lower $\varepsilon$, the higher $\tau^{\circ}$ is needed to reduce the marginal cost of abandoning the existing privileges.

When revenue from consumption taxes is not used for transfers at all $(\varepsilon=0$ ), the consumption tax does not have any real effects. If this is a case, an increase in consumption taxes will lead to a decrease in voluntary tax burden by the same amount, so that private consumption and the demand for public spending remain intact. The relative price of private consumption in terms of public spending (i.e., $(1+\varepsilon \tau) \frac{r}{\rho}$ ) would change with the consumption tax only if some of consumption taxes are returned to the private sector in a lump-sum way.

Next, let us consider the perfect Nash equilibrium. At the closed loop solution we now have

$$
\begin{aligned}
& \tilde{\beta}_{1}(\tau) \equiv-\frac{\beta_{1}}{1+\tau}+\frac{\gamma_{1}(Y+T)}{(1+\tau)^{2}} \\
& \tilde{\gamma}_{1}(\tau) \equiv \frac{\gamma_{1}}{(1+\tau)^{2}}
\end{aligned}
$$

And in place of equation (24)

$$
U_{c}=V_{G}(1+\tau)\left[r-\frac{(1-\varepsilon) r \tau}{1+\tau}\right]
$$

Thus, in order to realize the Pareto efficient allocation at the closed-loop steady-state solution, considering (15) and (31), we have the following condition:

$$
n=\pi(1+\varepsilon \tau)
$$


where $\pi \equiv \frac{\rho V_{G}}{U_{G}}<1$ from the first inequality in (25) and $\pi$ is evaluated at the closed-loop steady state values of $c$ and $G$. The optimal consumption tax rate at the closed-loop steady-state solution, $\tau^{s}$, is then given by

$$
\tau^{s}=\frac{n-\pi}{\varepsilon \pi}
$$

Note that equation (32) is not an explicit solution for $\tau^{s}$ as $\pi$ is dependent on $\tau^{s}$. Nevertheless, since $\pi<1$, we can say that the optimal consumption tax rate is smaller at the open-loop solution than at the closed-loop solution; that is, $\tau^{0}<\tau^{S}$. Intuitively, since the free-riding of each interest group is more severe at the closed-loop solution than that at the open-loop solution, a higher rate of the consumption tax is required to rectify it by reducing the marginal benefit of enjoying group-specific privileges more at the former solution. Note also that when revenue from consumption taxes is not used for transfers at all $(\varepsilon=0)$, the consumption tax does not have any real effects at the closed-loop solution as well.

\section{Adjustment speed}

As shown in Appendix 2, the adjustment speeds of $G$ under the Pareto efficient path, the open-loop path, and the closed-loop path are respectively given as

$$
\begin{aligned}
& D^{P}=\frac{\rho-\sqrt{\rho^{2}+4 \frac{\gamma_{2}}{\gamma_{1}} r^{2} n^{2}}}{2} \\
& D^{o}=\frac{\rho-\sqrt{\rho^{2}+4 \frac{\gamma_{2}}{\gamma_{1}} r^{2} n}}{2}
\end{aligned}
$$




$$
D^{S}=n \frac{\frac{\rho}{2}-\sqrt{\left(\frac{\rho}{2}\right)^{2}+\frac{\gamma_{2}}{\gamma_{1}} r^{2}(2 n-1)}}{2 n-1}
$$

A close observation of these adjustment speeds reveals that at any strategies the adjustment speed of fiscal reconstruction (in the absolute value) increases with $\gamma_{2}, r$ and $n$ but decreases with $\gamma_{1}$ and $\rho$. The negative effect of $\gamma_{1}$ reflects the fact that the larger $\gamma_{1}$, the less willing each group is to accept larger instantaneous changes in $g$. The more the future utilities are discounted (i.e., the larger $\rho$ ), the more time is needed to attain the balanced budget on the paths of any strategies. Interpreting this result in the context of overlapping generations economies, if the current generation does not much care of future generations, the pace of fiscal reconstruction slows down regardless of which type of strategies each interest group plays. These results are intuitively appealing.

Comparing (33-1) and (33-2), it is easy to see in the absolute value

$$
\left|D^{P}\right|>\left|D^{O}\right|
$$

The adjustment speed of a Pareto efficient path is greater in the absolute value than that of an open-loop equilibrium path.

Let us then compare (33-2) and (33-3). From (33-2) we have

$$
D^{\circ}-\frac{\rho}{2}=-\sqrt{\left(\frac{\rho}{2}\right)^{2}+\frac{\gamma_{2}}{\gamma_{1}} r^{2} n}
$$

On the other hand, from (33-3) we have

$$
D^{S}-\frac{\rho}{2}=\frac{1-n}{2 n-1} \frac{\rho}{2}-\sqrt{\frac{n^{2}}{(2 n-1)^{2}}\left(\frac{\rho}{2}\right)^{2}+\frac{\gamma_{2}}{\gamma_{1}} r^{2} \frac{n^{2}}{2 n-1}}
$$

It is tedious but straightforward to show (see Appendix 4) that 


$$
\left(D^{O}-\frac{\rho}{2}\right)^{2}>\left(D^{s}-\frac{\rho}{2}\right)^{2}
$$

which means

$$
\left|D^{\circ}\right|>\left|D^{s}\right|
$$

Thus, the adjustment speed of the open-loop equilibrium path is greater in the absolute value than that of the closed-loop equilibrium path. At the open-loop solution each interest group sticks to the original reconstruction plan that was calculated at the beginning of the planning period and thus ignores the information on government spending that unravels over time. In contrast, since at the closed-loop solution each interest group observes the realization of $G$ at each point in time, the higher realized value of $G$ discourages the willingness of each group to accept tax increases and hence depresses the accumulation speed of $G$.

Let us then examine the impact of consumption taxes on the adjustment speed of fiscal reconstruction under open-loop and closed-loop paths. In the open-loop equilibrium with the consumption tax rate the adjustment speed (33-2) is rewritten as

$$
D^{o}(\tau)=\frac{\rho-\sqrt{\rho^{2}+4 \frac{\gamma_{2}}{\gamma_{1}} r^{2}(1+\varepsilon \tau)^{2} n}}{2}
$$

Since $(1+\varepsilon \tau)$ is increasing with $\tau$, the adjustment speed (or the absolute value) of $D^{\circ}$ is increasing with the consumption tax rate.

In the closed-loop equilibrium with consumption taxes the adjustment speed is rewritten as

$$
D^{S}(\tau)=n \frac{\frac{\rho}{2}-\sqrt{\left(\frac{\rho}{2}\right)^{2}+\frac{\gamma_{2}}{\gamma_{1}} r^{2}(1+\varepsilon \tau)^{2}(2 n-1)}}{2 n-1}
$$

The adjustment speed is again increasing with the consumption tax rate. Note also that 
at either strategy the larger the value of $\varepsilon$, the greater the effect of the consumption tax on the adjustment speed. In other words, in order to make the consumption tax more effective in promoting fiscal reconstruction, we have to raise the propensity to transfer $\varepsilon$ as well as the consumption tax at the same time.

We have shown that the adjustment speed of the Pareto efficient path is greater than that of the open-loop equilibrium path, and the adjustment speed of the open-loop equilibrium path is greater than that of the closed-loop equilibrium path. An increase in the consumption tax will raise the adjustment speed of fiscal reconstruction in either noncooperative equilibrium and hence it is desirable in terms of the adjustment speed. This result is very similar to Proposition 2 of Alesina and Drazen (1991) in which a slower growth of government debts caused by financing the greater fraction of government expenditures via distortionary taxation hastens the timing of fiscal reconstruction. However, the reason for their result is different from ours; that is, in their model increased distortionary taxes generate a greater distortion for a given deficit which is borne by the interest groups involved, inducing earlier concession of those groups. In our model an increase in consumption taxes raises the relative price of consumption, which is the marginal cost of privileges, inducing earlier abandon of groups-specific privileges. In addition, an introduction of (or an increase in) $\tau$ will raise the speed of fiscal reconstruction and will reduce the steady state level of $B$ (and thus raise the steady state level of $G$ ). The dynamic motions of $B$ as well as $G$ become closer to the Pareto efficient ones.

\section{Conclusion}

We have shown that the free riding problem in the fiscal reconstruction process is aggravated when players' contributions are conditional on the observable 
collective contributions. In other words, without commitment lower contributions, higher existing privileges, and higher government debt are made relative to the enforceable commitment case. The most important policy's lesson from the present analysis is that if the program of fiscal reconstruction is too flexible in the sense that it allows each interest group to reconsider the predetermined policies such as tax increases or subsidy cuts at each point in time when the outcome of fiscal reconstruction is revealed, it is highly likely that fiscal reconstruction ends finally in much failure. Our result indicates that allowing such possibility would strengthen an incentive of each group to free ride. In order to realize successful fiscal reconstruction, therefore, we have to stick to the long-term program for fiscal reconstruction that has been agreed at the beginning of planning period. In practice, one of effective means is to enact legislation for fiscal reconstruction which does not permit much room for reconsidering or revising the fiscal reconstruction plan later on (e.g., the GrammRudman-Hottings Act in the United States).

We have also derived explicitly the adjustment speed of public spending or public debt under alternative solutions and shown that the adjustment speed of the Pareto efficient path is greater than that of the open-loop equilibrium path under the plausible utility function. We have also shown that the adjustment speed of the openloop equilibrium path is greater than that of the closed-loop equilibrium path. In words, allowing the possibility of revising the plan of fiscal reconstruction tends to slow down the speed of fiscal reconstruction adjustment.

We have finally shown that the optimal consumption tax rate at the open-loop or closed-loop solution is increasing with the number of groups and decreasing with the portion of consumption taxes to be used for lump-sum transfers. The optimal consumption tax rate is smaller at the open-loop solution than at the closed-loop 
solution. The consumption tax can be used for attaining the Pareto-efficient fiscal reconstruction not because it produces much revenue but because it reduces the marginal benefit of enjoying group-specific privileges thereby inducing each interest group to abandon its privileges earlier. When revenue from consumption taxes is not used for transfers at all, the consumption tax does not have any real effects at the open-loop or closed-loop solution. The relative price of private consumption in terms of public good would change with the tax rate only if some of consumption taxes are returned to the private sector in a lump-sum way. Furthermore, another important policy implication of the present analysis is that in order to make the consumption tax policy more effective as an instrument for fiscal reconstruction, the fraction of tax revenue which is returned to the interest groups involved should be raised so as to induce their voluntary acceptance of tax increases more easily.

The present model could be extended in several directions. The most important extension is to allow heterogeneity across interest groups as in Alesina and Drazen (1991) and Bulow and Klemperer (1997). In their model based on "a war of attrition", heterogeneity in terms of the cost of waiting plays a crucial role in determining the timing (i.e., the speed) of fiscal reconstruction. Recently, Grossman and Helpman (1996) focuses on heterogeneous interest groups' use of campaign contributions as a vehicle for influencing public policy. Although heterogeneity is not crucial to our model, the extension to include heterogeneous interest groups in terms of incomes, preferences, or discount factors may add further insights to our results despite the analytic complexity. Finally, we have assumed that the government is going to reconstruct its budget and then the question was how should it do it. It would be useful to explain the reason for the fiscal crisis as well as the fiscal reconstruction based on the selfish behavior of interest groups. 
Appendix 1: Closed-loop solution

Consider the quadratic value function

$$
V^{i}(G)=\theta_{0}+\theta_{1} \gamma_{1} G+\frac{\theta_{2}}{2} \gamma_{1} G^{2}
$$

Differentiating this value function yields

$$
V_{G}^{i}=\theta_{1} \gamma_{1}+\theta_{2} \gamma_{1} G
$$

Substituting this into (21), we have

$$
g_{i}=\kappa_{1}^{s}+\kappa_{2}^{s} G
$$

where

$$
\begin{aligned}
& \kappa_{1}^{s} \equiv \frac{\widetilde{\beta}_{1}}{\gamma_{1}}+\theta_{1} r \\
& \kappa_{2}^{s} \equiv r \theta_{2}
\end{aligned}
$$

Substitute this $g_{i}$ function (A2), $V^{i}(G)$, and $V_{G}^{i}$ into the functional equation (20). Then, we have

$$
\begin{aligned}
& \rho\left[\theta_{0}+\theta_{1} \gamma_{1} G+\frac{1}{2} \gamma_{1} \theta_{2} G^{2}\right]=\tilde{\alpha}+\tilde{\beta}_{1}\left[\frac{\tilde{\beta}_{1}}{\gamma_{1}}+\left(\theta_{1}+\theta_{2} G\right) r\right]+\beta_{2} G \\
& -\frac{\gamma_{1}}{2}\left\{\frac{\tilde{\beta}_{1}}{\gamma_{1}}+\left(\theta_{1}+\theta_{2} G\right) r\right\}^{2}-\frac{\gamma_{2}}{2} G^{2}+\left(\gamma_{1} \theta_{1}+\gamma_{1} \theta_{2} G\right)\left\{n r g_{i}-r G^{*}\right\}
\end{aligned}
$$

Or equivalently

$$
\begin{aligned}
& 0=-\rho\left[\theta_{0}+\gamma_{1} \theta_{1} G+\frac{1}{2} \gamma_{1} \theta_{2} G^{2}\right]+\widetilde{\alpha}+\frac{\tilde{\beta}_{1}^{2}}{\gamma_{1}}+\tilde{\beta}_{1}\left(\theta_{1}+\theta_{2} G\right) r+\beta_{2} G- \\
& \frac{\gamma_{1}}{2}\left\{\left(\frac{\tilde{\beta}_{1}}{\gamma_{1}}\right)^{2}+\frac{2 \tilde{\beta}_{1}}{\gamma_{1}}\left(\theta_{1}+\theta_{2} G\right) r+\left(\theta_{1}^{2}+2 \theta_{1} \theta_{2} G+\theta_{2}^{2} G^{2}\right) r^{2}\right\}-\frac{\gamma_{2}}{2} G^{2}+ \\
& \left(\gamma_{1} \theta_{1}+\gamma_{1} \theta_{2} G\right)\left[n r \frac{\tilde{\beta}_{1}}{\gamma_{1}}+n\left(\theta_{1}+\theta_{2} G\right) r^{2}-r G^{*}\right]
\end{aligned}
$$

Since this equation must be satisfied for every possible $G$, the constant term and each of the coefficients of the $G$-terms on the right hand side of this equation must be zero. 
This requirement generates the following system of equations in the value function parameters. Because of the assumed symmetry of value functions, an identical system of equations is generated for each group. The equation corresponding to the coefficient of the $G^{2}$-term is given by

$$
-\frac{\rho}{2} \gamma_{1} \theta_{2}-\frac{\gamma_{1}}{2} \theta_{2}^{2} r^{2}-\frac{\gamma_{2}}{2}+\gamma_{1} \theta_{2} n \theta_{2} r^{2}=0
$$

Or equivalently

$$
\gamma_{1} r^{2}\left(\frac{2 n-1}{2}\right) \theta_{2}^{2}-\gamma_{1} \frac{r}{2} \theta_{2}-\frac{\gamma_{2}}{2}=0
$$

Applying the quadratic formula, we have

$$
\theta_{2}=\frac{\frac{\rho}{2} \pm \sqrt{\left(\frac{\rho}{2}\right)^{2}+\frac{\gamma_{2}}{\gamma_{1}} r^{2}(2 n-1)}}{r^{2}(2 n-1)}
$$

Let denote these two roots $\lambda_{1}$ and $\lambda_{2}$, respectively. They are real, because

$$
\left(\frac{\rho}{2}\right)^{2}+\frac{\gamma_{2}}{\gamma_{1}} r^{2}(2 n-1)>0
$$

Moreover, it is clear that one root is positive and the other root is negative, i.e.,

$$
\lambda_{1}<0<\lambda_{2}
$$

As shown later (from the stability analysis in Appendix 2), $\lambda_{1}$ is the only root for $\theta_{2}$.

The equation which corresponds to the coefficient of the $G$-term is given by

$$
\begin{aligned}
& -\rho \gamma_{1} \theta_{1}+\tilde{\beta}_{1} \theta_{2} r+\beta_{2}-\frac{\gamma_{1}}{2} 2 \frac{\tilde{\beta}_{1}}{\gamma_{1}} \theta_{2} r-\frac{\gamma_{1}}{2} 2 \theta_{1} \theta_{2} r^{2}+\gamma_{1} \theta_{1} n \theta_{2} r^{2} \\
& \gamma_{1} \theta_{2} n r \frac{\tilde{\beta}_{1}}{\gamma_{1}}+\gamma_{1} \theta_{2} n \theta_{1} r^{2}-\gamma_{1} \theta_{2} r G^{*}=0
\end{aligned}
$$

Or equivalently

$$
-\rho \gamma_{1} \theta_{1}+\beta_{2}+(2 n-1) \gamma_{1} \theta_{1} \theta_{2} r^{2}+\theta_{2} n r \tilde{\beta}_{1}-\gamma_{1} \theta_{2} r G^{*}=0
$$


Substituting $\lambda_{1}$ into $\theta_{2}$ in (AG) yields

$$
\theta_{1}=\frac{\beta_{2}+\lambda_{1} n \cdot \tilde{\beta}_{1}-\gamma_{1} \lambda_{1} r G^{*}}{\rho \gamma_{1}-(2 n-1) \gamma_{1} \lambda_{1} r^{2}}
$$

Since $\tilde{\beta}_{1} \equiv-\beta_{1}+\gamma_{1} Y<0$, we can show that $\lambda_{1} n r \tilde{\beta}_{1}-\gamma_{1} \lambda_{1} r G^{*}>0$ and hence $\theta_{1}>0$.

Appendix 2: Stability

Let us then investigate the stability property of the Pareto efficient fiscal reconstruction path. The system is given by

$$
\left[\begin{array}{l}
\dot{\mu} \\
\dot{G}
\end{array}\right]=\left[\begin{array}{cc}
\rho & n \gamma_{2} \\
\frac{r^{2} n}{\gamma_{1}} & 0
\end{array}\right]\left[\begin{array}{l}
\mu \\
G
\end{array}\right]+\left[\begin{array}{c}
-\beta_{2} n \\
r n\left(Y-\frac{\beta_{1}}{\gamma_{1}}\right)
\end{array}\right]
$$

The characteristic equation is given by

$$
(p-q)(-q)-\frac{\gamma_{2}}{\gamma_{1}} r^{2} n^{2}=0
$$

We have

$$
q=\frac{\rho \pm \sqrt{\rho^{2}+4 \frac{\gamma_{1}}{\gamma_{2}} r^{2} n}}{2}
$$

That is, the two roots are real, one positive and the other negative. Thus, if we take the stable solution and use the initial condition, we get the equilibrium path

$$
G(t)=G^{*}+\left(G(0)-G^{*}\right) e^{D^{p} t}
$$

where

$$
D^{P}=\frac{\rho-\sqrt{\rho^{2}+4 \frac{\gamma_{2}}{\gamma_{1}} r^{2} n^{2}}}{2}<0
$$

The system is globally asymptotic stable. 
The system of the open-loop equilibrium path is given by

$$
\left[\begin{array}{l}
\dot{\mu} \\
\dot{G}
\end{array}\right]=\left[\begin{array}{cc}
\rho & \gamma_{2} \\
\frac{r^{2} n}{\gamma_{1}} & 0
\end{array}\right]\left[\begin{array}{l}
\mu \\
G
\end{array}\right]+\left[\begin{array}{c}
-\beta_{2} \\
\ln \left(Y-\frac{\beta_{1}}{\gamma_{1}}\right)
\end{array}\right]
$$

The characteristic equation is given as

$$
(\rho-q)(-q)-\frac{\gamma_{2}}{\gamma_{1}} r^{2} n=0
$$

Applying the quadratic formula, we have

$$
q=\frac{\rho \pm \sqrt{\rho^{2}+4 \frac{\gamma_{2}}{\gamma_{1}} r^{2} n}}{2}
$$

Thus, we get the equilibrium path

$$
G(t)=G^{*}+\left(G(0)-G^{*}\right) e^{D^{0} t}
$$

where

$$
D^{0}=\frac{\rho-\sqrt{\rho^{2}+4 \frac{\gamma_{2}}{\gamma_{1}} r^{2} n}}{2}<0
$$

This path is globally asymptotic stable.

Finally, let us investigate the closed-loop equilibrium path. After substituting (A3), the solution of homogeneous part of

$$
\dot{G}-n r \kappa_{2}^{s} G=0
$$

is

$$
G(t)=M e^{D^{s} t}
$$

where since $\kappa_{2}^{s}<0$, we know that

$$
D^{s} \equiv n r \kappa_{2}^{s}<0
$$


and $M$ is the constant of integration. We get the feedback Nash equilibrium contribution path, which is given as

$$
G(l)=\bar{G}^{s}+\left(G(0)-G^{*}\right) e^{D^{s}}
$$

Note that the negativity of $D^{S}$ guarantees that the equilibrium path is globally asymptotic stable.

Appendix 3: Derivation of (25)

Let us compare $U_{G} / \rho$ and $V_{G}$. We investigate the sign of

$$
Q \equiv \theta_{1} \gamma_{1}+\theta_{2} \gamma_{2} G-\left[\frac{\beta_{2}}{\rho}-\frac{\gamma_{2}}{\rho} G\right]
$$

From (A6)

$$
\begin{aligned}
& \rho \gamma_{1} \theta_{1}-\beta_{2}=\theta_{2} \theta_{1} \gamma_{1} r^{2}(2 n-1)+\theta_{2} n r \widetilde{\beta}_{1}-\gamma_{1} \theta_{2} r G^{*} \\
& =\theta_{2}\left[\theta_{1} \gamma_{1} r^{2}(n-1)+\theta_{1} \gamma_{1} r^{2} n+n r \widetilde{\beta}_{1}-\gamma_{1} r G^{*}\right]
\end{aligned}
$$

From $\kappa_{1}^{s}, \kappa_{2}^{s}$ we also know

$$
\theta_{1} \gamma_{1} r^{2} n+n r \tilde{\beta}_{1}-\gamma_{1} r G^{*}=\gamma_{1}\left(-n r^{2} \theta_{2}\right) G
$$

Substituting (A20) into (A19), $Q$ reduces to

$$
Q=\frac{\theta_{2}}{\rho}\left[\theta_{1} \gamma_{1} r^{2}(n-1)+\gamma_{1}\left(-n r^{2} \theta_{2}\right) G\right]+\left[\theta_{2} \gamma_{1}+\frac{\gamma_{2}}{\rho}\right] G
$$

Note that from (A4) we have

$$
r^{2}(2 n-1) \theta_{2}^{2}=\rho \theta_{2}+\frac{\gamma_{2}}{\gamma_{1}}
$$

Substituting (A22) into (A21), we have 


$$
\begin{aligned}
Q & =\frac{\theta_{2} \gamma_{1} r^{2}(n-1)}{\rho}\left[\theta_{1}+\frac{1}{r^{2}(n-1)}\left(-n r^{2} \theta_{2}+\rho+\frac{\gamma_{2}}{\gamma_{1} \theta_{2}}\right) G\right] \\
& =\frac{\theta_{2} \gamma_{1} r^{2}(n-1)}{\rho}\left[\theta_{1}+\theta_{2} G\right]
\end{aligned}
$$

which is negative since $V_{G}>0$.

Appendix 4: Adjustment speed

Let us compare $D^{o}-\frac{\rho}{2}$ and $D^{s}-\frac{\rho}{2}$.

$$
\left(D^{o}-\frac{\rho}{2}\right)^{2}-S_{1}=\frac{2 n(n-1)}{(2 n-1)^{2}}\left[(\rho)^{2}+\frac{\gamma_{2}}{\gamma_{1}} r^{2} \frac{2 n-1}{2}\right]
$$

where

$$
S_{1} \equiv \frac{(n-1)^{2}}{(2 n-1)^{2}}\left(\frac{\rho}{2}\right)^{2}+\frac{n^{2}}{(2 n-1)^{2}}\left(\frac{\rho}{2}\right)^{2}+\frac{n^{2}}{2 n-1} \frac{\gamma_{2}}{\gamma_{1}} r^{2}
$$

On the other hand we have

$$
\left(D^{S}-\frac{\rho}{2}\right)^{2}=S_{1}+S_{2}
$$

where

$$
S_{2} \equiv \frac{2 n(n-1)}{(2 n-1)^{2}}\left(\frac{\rho}{2}\right) \sqrt{\left(\frac{\rho}{2}\right)^{2}+\frac{\gamma_{2}}{\gamma_{1}} r^{2}(2 n-1)}
$$

Since $\left(D^{O}-\frac{\rho}{2}\right)^{2}-S_{1}>S_{2}$, we obtain $\left(D^{O}-\frac{\rho}{2}\right)^{2}>\left(D^{s}-\frac{\rho}{2}\right)^{2}$. 


\section{References}

Alesina. A. and G. Tabellini, 1990, A positive theory of fiscal deficits and government debt, Review of Economic Studies 57, 403-414.

Alesina, A. and A. Drazen, 1991, Why are stabilization delayed?, American Economic Review 81, 1170-1188.

Barro, R., 1974, Are government bonds net wealth?, Journal of Political Economy 87, $940-971$

Bliss, C. and B. Nalebuff, 1984, Dragon-slaying and ballroom dancing: the private supply of a public good, Journal of Public Economics 25, 1-12.

Boardway, R., Pestieau, P. and D. Wildasin, 1989, Tax-transfer policy and the voluntary provision of public goods, Journal of Public Economics 39, 157-176.

Bulow, J. and P. Klemperer, 1997, The generalized war of attrition, NBER working paper 5872

Fershtman, C. and M.I. Kamien, 1987, Dynamic duopolistic competition with sticky prices, Econometrica 55, 1151-1174.

Fershtman, C. and S. Nitzan, 1991, Dynamic voluntary provision of public goods, European Economic Review 35, 1057-1067.

Futagami, K., 1989, A game theoretic approach to reconstruction of public finance, Journal of Public Economics 40, 135-150.

Grossman, G.M. and E. Helpman, 1996, Electoral competition and special interest politics, Review of Economic Studies 63, 265-286.

Ihori, T, and J. Itaya, 1997, Dynamic provision of public goods as environmental externalities, mimeo. 
McGuire, M.C.. 1974, Group size. group homogeneity, and the aggregate provision of a pure public good under Cournot behavior, Public Choice 18, 107-126.

Roubini, N. and G. M. Milesi-Ferretti, 1994, Optimal taxation of human and physical . capital in endogenous growth models, NBER working paper no. 4882. 


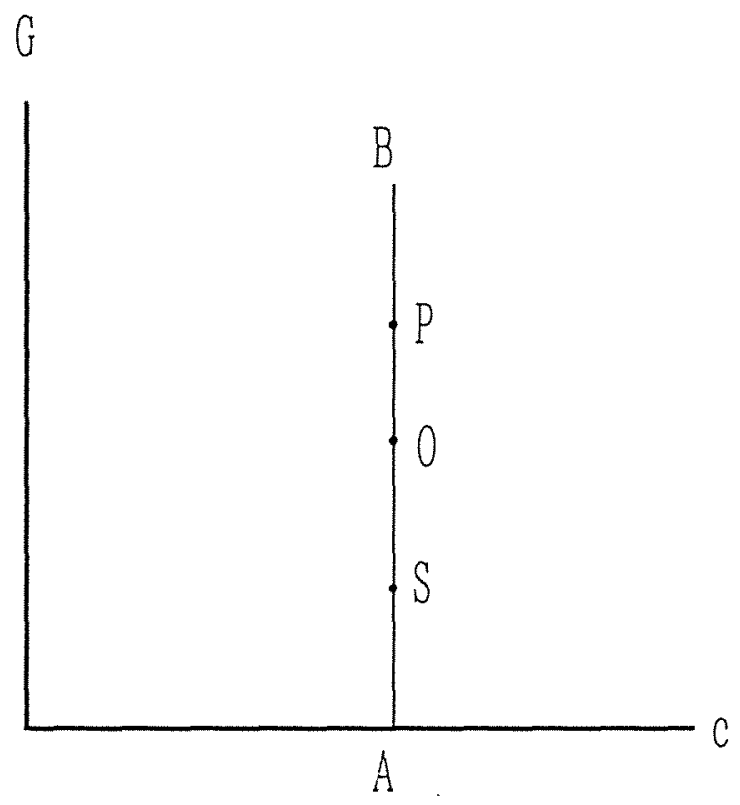

Figure 1 
This Discussion paper Series is published by the Institute of Economic Research and integrates two old ones published separately by the Department of Economics and the Department of Commerce.

Discussion Paper Series

Institute of Economic Research

otaru University of Commerce

No.

Title

1.末ーキンズ=サイモンの条件に閉する諸説の統台について

2. Motivation and Cusal Inferences in the Budgetary Control

3. Проблемы управления ра 6 о чей

силой на предприя тия х Дальнего

Востока(социологические аспекты)

author/s

多スグプ多、゙イパンー

Yoshihiro Naka

A. н а т о ли й

Миха й Л В Вич $\mathrm{H}$

Ш $\mathrm{\kappa} \mathrm{y} \mathrm{p} \mathrm{и}$

4. Dynamic Tax Incidence in a Finite Horizon Kodel

5. Business Cycles with Asset Price Bubbles and the Bole of Monetary Policy

6. Continuous Double-Sided Auctions in Eoreign Exchange Markets

7. The Existence of Ramsey Equilibrium with Consumption Externality

8. Money, Neutrality of Consumption Taxes, and Growth in Intertemporal Optimizing Models

9. Product Returns in the Japanese Distribution System:A Case Study of a Japanese tholesaler's Return Reduction Efforts

10. Dynamics, Consistent Conjectures and Heterogeneous Agents in the Private Provision of Public Goods

11. Intra-industry Investment and Imperfect Markets A Geometric approach in Simple General Equilibrium

12. Sit-Dwon to Split:Flint GM Horkers in 1937-1939

13. The Complementarity between Endogenous Protection and Direct foreign Investment

14. Consumtion Taxation and Tax Prepayment approach in Dynamic General equilibrium Models with Consumer Durables

15. Regulatory System and Supervision of the Financial Institutions in Japan

16. Financial Restructuring and the U. S. Regulatory Framework

17. The Legacy of the Bubble Economy in Japan:Declining cross Shareholding and Capital Formation

18. Stockownership in the U. S.:Capital formation and regulation

19. International Joint Ventures and Endogenous Protection a Political-Economy Approach

20.GM社をめぐるア归力労物史研究：ファインとエッッ゙フォースの現場像の吟昧

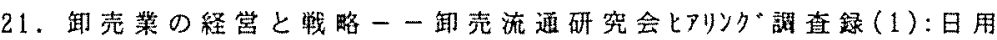
篗货觢売企業

22. 卸売業の経営と戦路——卸売流通研究会七アリyダ調查録(2): 食品・ 酒類缷売企業
Jun-ichi Itaya

Jan. 1993

Hiroshi Shibuya

Jun. 1993

Ryosuke Wada

Aug. 1993

Sadao Kanaya suka

\& Tomoichi Shinot

Jun-ichi Itaya

Nov. 1993

Jeffery Alan Brunson

Mar. 1994

Jun-ichi I taya

Jun. 1994

\& Dipankar Dasgupta

Laixun Zhao

oct. 1994

Satoshi Takata

Dec. 1994

Laixun Zhao

Feb. 1995

Jun-ichi Itaya

Mar. 1995

Os amu I to

May 1995

Jane W. D'Arista

May 1995

Hiroo Hojo

May 1995

Marshall E. Blume

May 1995

Laixun Zhao

Nov. 1995

舀田聡

Feb. 1996

卸壳流通研究会

（代表高宮城朝別）

卸売流通研究会

（代表高宮城朝别）
Apr. 1996

Apr. 1996 
23. A Note on the Impacts of Price Shocks on Wage in Unionized Economies

24. Transfer Pricing and the Nature of the subsidiary firm

25. The Incidence of a Tax on Pure in an Altruistic overlapping Generations Econony

26. 'Small Government' in the 21 st Century

27. Characteristics and Reforms of Public Health Insurance System in Japan

28. The Role of Local Governments in Urban Development Policy

29. Optimal Taxation and the Private Provision of Public Goods

30. Comparison of Agricultural Policy in the U. S. and the Japan

31. US Health Insurance:Types, Patterns of Coverate and Constraints to Reform

32. International Capital Flows and National Macroeconomic Policies

33. Financial Liberalization and Securitization in Houshing Finance and the Changing Roles of the Government

34. Social Efficiency and the 'Market Revolution' in US Houshing Finance

35. Government Expenditure and the Balance of Payments:Budget Deficit, Financial Integration, and Economic Diplomacy

36. A History of $P B G C$ and Its Roles

37. Dynamic Provision of Public Goods as Environmental Externalities

38. A Comparative Static Analysis of the Balanced Budget Incidence in the Presence of Sector-Specific Unemployment

39. An Econometric Study of Trade Creation and Trade Diversion in Endoh Masahiro the EEC,LAFTA and CMEA:A Simple Application of the Gravity Model

40. A Dynamic Model of Eiscal Reconstruction

Discussion Paper Series

Department of Economics

otaru University of Commerce

No.

Title

1. Monetary Policy in a Model of International Trade with a Sector Sticky Wage Rate

2. Export Credit Insurance

3. Asset Tarding in an 0verlapping-Generations Model:Efficiency of Competitive Equibriug

4. Asset Tarding in an Overlapping-Generations Model with Production Shocks

5. Immiserizing Investment in a Vertically Related International Trade
Laixun thao

May 1996

Laixun Zhao

Jun. 1996

Jun-ichi Itaya

Sep. 1996

Hiroshi Shibuya

Sep. 1996

Takashi Nakahama

Sep. 1996

Yoshinori Akiyama

Sep.1996

Jun-ichi Itaya

\& David de Meza

\& Gareth D. Myles

Toshikazu Tateiwa

0 ct. 1996

Dwayne A. Banks

oct. 1996

Jane H. D'Arista

oct. 1996

Syn-ya Imura

oct.1996

Gary Dymski

oct. 1996

\& Dorene Isenberg

Hiroshi Shibuya

Nov. 1996

C. David Gustafson

Nov. 1996

Toshiniro Ihori

\& Jun-ichi Itaya

Koh Sumino

Mar.1997

Apr. 1997

Toshihiro Ihori \& Jun-ichi Itaya

Apr. 1997

$\begin{array}{ll}\text { author/s } & \text { Date } \\ \begin{array}{ll}\text { Takashi Fukushima } \\ \text { \& Hideki Funatsu }\end{array} & \text { Feb.1985 } \\ \text { Hideki Funatsu } & \text { Feb.1985 } \\ \text { Kenji Ymamoto } & \text { Oct.1985 } \\ \text { Kenji Ymamoto } & \text { Oct.1985 } \\ \text { Masao Satake } & \text { Mar. } 1986\end{array}$


6. Dynamic Tax Incidence in a Two-Class Economy

\begin{tabular}{|c|c|}
\hline Jun-ichi Itaya & May 1986 \\
\hline Hideki Funatsu & May 1986 \\
\hline
\end{tabular}

7. A Three Factor Model of International Trade with Minimum

Hideki Funatsu

Nov. 1986

8. A Note of the Maximum Number of Firms with Equal Market Share

Masaru Uzara in a Quantity Setting Supergame

9. Tax Incidence in a Two-Sector Growing Economy with Perfcet

Jun-ichi Itaya

May 1987 Foresight

10. Two Kinds of Information in price Search

Kaoru Endo

Aug. 1987

\& Teruya Nagao

Oct. 1987

11. On the Hedging and Investment Behavior of the Competitive Firm under Price Uncertainty

Jun-ichi Itaya

12. Tax Incidence in a two-Secot Growing Economy with Perfect Foresight:Long-Run Analysis

Jun-ichi I taya

Mar. 1988

13. Comparative Statics for the Private Provision of Public Goods in a Conjectural Variations Model with Heterogeneneous Agents

Dipankar Dasgupta

Mar. 1991

\& Jun-ichi Itaya

Mar. 1991

14. Capital Accumulation Game of Multifirms with External

Jun-ichi Itaya

Ju1. 1991

15. Using the Correct Econonic Interpretation to Prove

Dipankar Dasgupta

the Howkins-Simon-Nikaido Theorem:One More Note

tomoichi Shinotsuka

$0 \mathrm{ct} .1991$

16. Taransversality condition in Infinite Time Horizon concave Problems

Discussion Paper Series

Department of Comarce

Otaru University of Commerce

No.

Title

author/s

Date

井上正

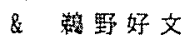

井上正

\& 粆影好文

Apг. 1985

May 1989

Institute of Economic Researchi, Otaru University of Commerce

3-5-21, Midori, 0taru, Hokkaido 047, Japan Tel.0134-27-5289

Fax. $0134-27-5293$

小梅科大学释済研究所

于047 北海道小榑市粶 3 丁目 5 番 21 号 Tel.0134-27-5289 Fax.0134-27-5293 